\title{
Social Media Marketing-The Paradigm Shift in International Marketing
}

\author{
S. Rama Krishna Chary \\ Research Scholar, Department of Commerce Osmania university, Hyderabad, Telangana, India
}

\begin{abstract}
Long time ago, marketing campaigns were confined to the traditional methods and yet they fulfilled all the needs of a marketer to create a buzz about their brand in the market at that time. In today's world, having a general idea of marketing a brand is not enough. The market demands creativity and along with it other attributes that can give you an edge over the others.

The answer to this need is Social Media marketing which, in such a short time, has reached staggering heights and has captured the attention of marketers worldwide. It goes without saying that social media has become a great platform to promote a brand owing to its wide reach and frequency of use.

There are a large number of factors contributing to success of social media as a marketing platform. When a marketer promotes his product, his primary aim is to reach to the right audience and understand their needs. One of the most important merits of social media is the "instant feedback" option that it provides to all its users. The users can comment on the posts and campaigns that are done as a part of marketing strategy which gives the marketer a fair idea of the needs and desires of its customers.

This paper/article examines how Social Media Marketing helps in reaching the target markets, how it is different from traditional marketing, the benefits of it, and with the conclusion that Social Media Marketing is an important marketing strategy that will continuously grow in both practice and demand all over the world.
\end{abstract}

Keywords: Marketing Campaigns, Creativity, Social Media Marketing, Marketing Strategy.

\section{Introduction:}

Social media marketing refers to the process of gaining website traffic or attention through social media sites. Social media marketing programs usually center on efforts to create content that attracts attention and encourages readers to share it with their social networks. The resulting electronic word of mouth (E-WoM) refers to any statement consumers share via the Internet (e.g., web sites, social networks, instant messages, news feeds) about an event, product, service, brand or company. When the underlying message spreads from user to user and presumably resonates because it appears to come from a trusted, third-party source, as opposed to the brand or company itself, this form of marketing results in 'earned media' rather than 'paid media'.

Social networking websites allow individuals to interact with one another and build relationships. When companies join the social channels, consumers can interact with them and they can communicate with consumers directly. That interaction feels more personal to users than traditional methods of strictly outbound marketing \& advertising.

Social networking sites and blogs allow individual followers to "re-tweet" or "re-post" comments made by the product being promoted. By repeating the message, all of the user's connections are able to see the message, therefore reaching more people. Social networking sites act as word of mouth. Because the information about the product is being put out there and is getting repeated, more traffic is brought to the product/company.

Benefits of Social Media Marketing:

- Improved social signals

- Company branding

- Improved brand awareness

- Word-of-mouth advertising

- Increased customer loyalty and trust

- Improved audience reach and influence

\section{Top 10 Social Media Marketing Tips for 2014}

Many social media sites started out as personal sites but social media marketing has become one of the most powerful online strategies for businesses, online and offline. These social sites are continually growing, expanding and changing and it can sometimes be difficult to keep up with these changes. Below are the top ten tips to help your social media marketing in 2014. 


\section{Make your posts more relevant}

When people first started using the social sites they were posting things like "Going shopping today with the kids. Wish me luck!" The social sites have grown and changed. You need to start posting more relevant information. Make it about your readers and followers, not about you. Post solutions, inspiration, and interesting facts that can be useful and helpful.

\section{Utilize features and tools}

Social sites are increasing the possibilities for your business with more tools and features than ever before. Take stock of all these tools and learn to use them for the benefit of your followers and your business.

\section{Visual Marketing}

Marketing is going visual and you need to do the same. Embed text and your business info in relevant graphics to post. Pictures are also the mostly widely used and shared method of posting on Face book. When people share your images you want them to see your website link or other relevant information.

\section{Help Your Clients/Readers}

No matter what business you are in, you cannot provide solutions to all your clients' needs. Be willing to post links, information and resources of other businesses that can help your clients where you cannot.

\section{Use Your Analytics}

Review your analytics regularly to see what is working and what isn't. Are people visiting one social site more than others? When are people visiting your pages? Find out everything you can from your results. You can learn a lot from your analytics but you must utilize them to reap the benefits.

\section{Host Events}

Hold regular events such as giveaways, seminars, chats, networking parties, promotions, etc. Facebook has recently updated their event feature so it is easier and more efficient.

\section{Connections Not Sales}

Use your social media pages to connect with your potential customers not for sales. You want to use social media to share information, respond to questions and comments and to showcase what your business is about. You don't want to continually bombard your social sites with sales pitches and ads. Help your followers find solutions, do not pitch to them.

\section{Slide share}

Slide share is predicted to be the fastest growing social site in 2013. Slide share will allow you to share your presentations with millions. You can also share documents, PDFs and videos. The possibilities are endless with this Slide share.

\section{Google+}

Google+ will be more important to your business. By being on Google+, you will be able to take full advantage of Google's many services and tools. It hasn't the social power of some of the other sites but it is a central part of Google and you should be a part of it.

\section{Use Fewer Social Sites}

Concentrating your marketing efforts to a few of the better producing sites is more effective than spreading yourself too thin over many of the social sites. The time it takes to successfully participate in social media is substantial so you need to build a strong presence on the sites that deliver rather than trying to dominate them all.

\section{Importance of Social Media Marketing:}

Social media gives marketers a voice and a way to communicate with peers, customers and potential consumers. It personalizes the "brand" and helps you to spread your message in a relaxed and conversational way. Social Media Marketing combined with Social Media Monitoring gives a marketer an opportunity to peek into the likes and dislikes of a prospective client and shape their campaigns accordingly. A check on the competitor's activities helps marketers to adapt their campaigns for better results.

People forget easily. It is important to remind them about your existence every now and then. Regular interactions play a major role in this respect. Posts and comments maintain a healthy relation between the brand and the client, helping them overcome any kind of communication barriers that might have existed otherwise. 
Social Media has established and promoted many brands, though it has rarely been used to its full potential. It has turned out to be a highly effective platform for marketing a brand. Social media marketing has helped establishing many brands and has helped them reach at the apex of the field. It will not be surprising if in future Social Media will beat traditional marketing methods to be the preferred choice of every marketer.

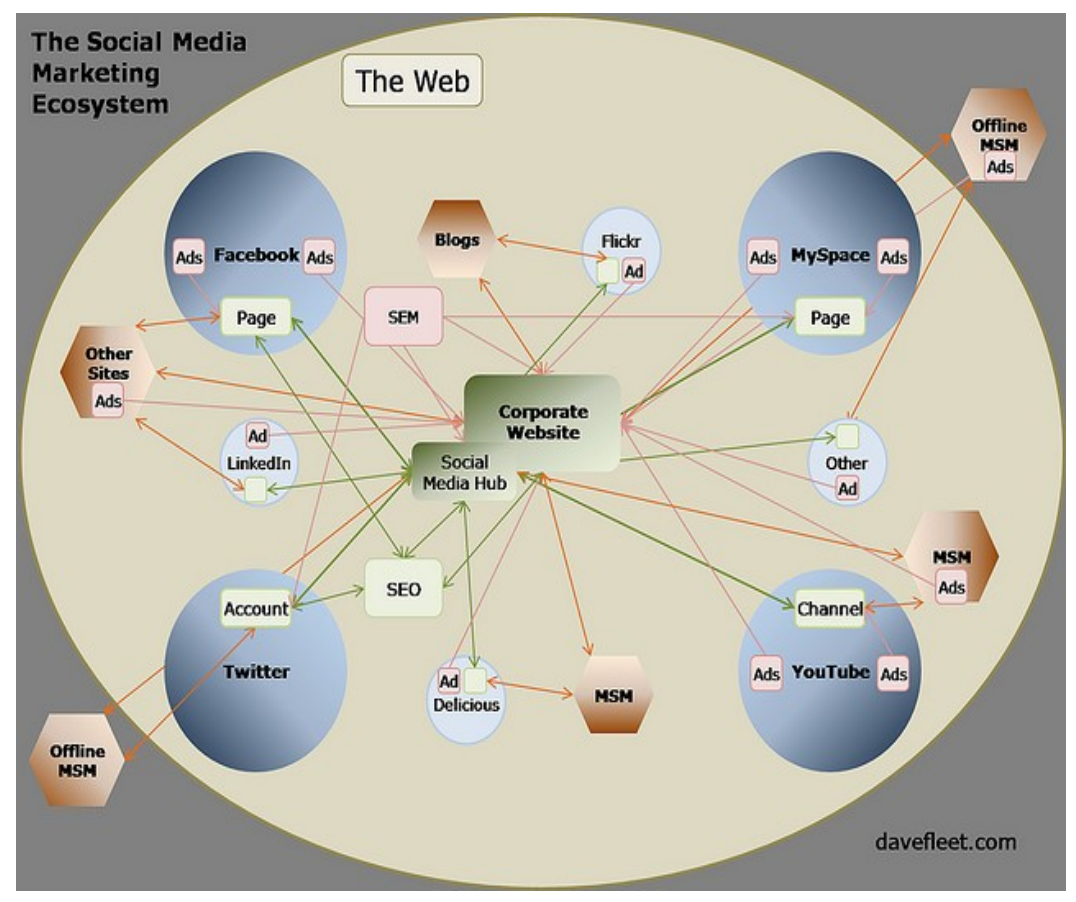

\section{Conclusion:}

Social media marketing is expected to reach new and unequaled heights in 2014. Don't let your business be left behind. Become active with social media. Really get involved. Make new connections and post relevant visual items. The role of social media in international marketing is to use it as a communication tool that makes you accessible to those interested in your product and makes you visible to those that don't know your product. Use it as a tool that creates a personality behind your brand and creates relationships that you otherwise may never gain. This creates not only repeat-buyers, but customer loyalty. The fact is social media is so diversified that it can be used in whatever way best suits the interests and the needs of your business.

\section{References:}

[1]. Assaad, Waad; Jorge Marx Gomez. Social Network in marketing (Social Media Marketing) Opportunities and Risks 2 (1). Retrieved 7 February 2013.

[2]. Evans, Dave (16 September 2010). Social Media Marketing: The Next Generation of Business Engagement. John Wiley \& Sons. pp. 15-. ISBN 978-0-470-94421-9. Retrieved 28 July 2013.

[3]. Muljadi, Paul and Paul Muljadi. p. 342. Digital Marketing Handbook.

[4]. Smith, Kay. "Kony 2012: The Ultimate Social Media Campaign?". Social Media Marketign. Business 2 Community. Retrieved 29 March 2012.

[5]. Kaplan Andreas M., Haenlein Michael (2010). "Users of the world, unite! The challenges and opportunities of social media".Business Horizons 53 (1). p. 61

[6]. Anderson, Kristin, and Carol Kerr. Customer Relationship Management. New York: McGraw-Hill, 2002.

[7]. Bain \& Company, Inc, "Management Tools and Trends 2005."

[8]. "A Crash Course in Customer Relationship Management." Harvard Business Review 1 March 2000.

[9]. Green, Paul, Tull (2002) "Research for Marketing Decisions", N. Delhi, Prentice-Hall of India

[10]. www.business-standard.com

[11]. Davefleet.com 